\title{
Identidade e participação política - o caso dos Enfermeiros nas eleições Autárquicas de 2013
}

\author{
Bruno de Noronha Gomes* \\ Jorge Adelino Cunha Ribeiro Pires ${ }^{* *}$ \\ * Instituto Superior de Ciências Sociais e Políticas da Universidade de Lisboa, Portugal \\ ** Associação Portuguesa de Enfermagem Militar, Portugal
}

\section{Resumo}

Este estudo de carácter exploratório constitui uma tentativa de analisar empiricamente a participação política dos enfermeiros, no caso como candidatos nas eleições autárquicas de Setembro de 2013. Tentou-se responder à questão de saber quem são enquanto profissionais e de que forma a sua profissão influencia a própria candidatura em termos programáticos, independentemente do partido ou movimento político em que participam. Além disso, procurou-se ainda perceber como vêm eles próprios a profissão. Pensamos que se conseguiu, assim, obter dados iniciais que permitam posteriormente uma análise teoricamente fundamentada.

Palavras-chave: enfermeiros; eleições autárquicas; participação política; representação social

\begin{abstract}
This study is an attempt to empirically study the political participation of nurses, in this case as candidates in the municipal elections of September 2013. Attempts have been made to answer the question of who they are as professionals and in what way their profession influences the candidacy itself in programmatic terms, regardless of the party or political movement in which they participate. In addition, we tried to understand how nurses see the profession itself. We think that we have been able to obtain initial data that will allow a further theoretically substantiated analysis.
\end{abstract}

Keywords: nurses; municipal; political participation; social representation 


\section{Introdução}

Os enfermeiros são o grupo de profissionais de saúde mais numeroso no país (mais de 71.000 registados), todavia, não é visível do ponto de vista sociopolítico a importância da profissão e do protagonismo que assume nas organizações de saúde ${ }^{[1]}$. Estarão alheios, mais do que outros grupos profissionais, ao processo político-partidário, ou trata-se apenas de uma questão de visibilidade e valorização da participação cívica e política enquanto profissionais? Assim, é decisivo responder a estas questões e identificar como e em que dimensão esta presença na política ocorre.

Não obstante a aparente parca participação política dos enfermeiros, de acordo com uma sondagem (PayScale, 2013) nos EUA a mais de 1,4 milhão de alunos, são os estudantes de enfermagem em maior percentagem (85\%), entre 13 profissões analisadas, os que consideram que a sua profissão pode mudar o mundo.

É escassa a literatura sobre o tema, no entanto alguns estudos em vários países indicam que os enfermeiros consideram poder influenciar as políticas governamentais (Gesse, 1991) na área da saúde. A participação e o envolvimento em debates políticos a todos os níveis pode resultar em ganhos na luta pelos seus direitos mas também podem tornar a profissão mais influente politicamente (Fyffe, 2009). Defendem estes autores que, comparando com a experiência nos EUA, importa promover o aumento da participação dos enfermeiros no processo político e na tomada de decisão na área da saúde.

Considerando a participação política dos enfermeiros, na qualidade de grupo profissional, como uma área de análise específica dentro da problemática da participação política, procurámos não descurar o seu enquadramento mais amplo, recorrendo para esse efeito a Borba (2012) e à sua análise da evolução deste fenómeno, para a qual recorre a autores como Milbrath (1965), Pizzorno (1966), Verba, Nie e Kim (1971, 1978), Kaase \& Marsh (1979), Verba, Scholozman \& Brady (1995) e Teorell, Torcal \& Montero (2007). A estes autores acrescentámos a perspetiva de Barbagli \& Maccelli (1985) e de Pasquino (2005).

Pasquino (2005) diz-nos que "Participação política é o conjunto de atos e de atitudes que aspiram a influenciar de forma mais ou menos direta e mais ou menos legal as decisões dos detentores do poder no sistema político ou em organizações políticas particulares, bem como a própria escolha daqueles, com o propósito de manter ou modificar a estrutura (e, consequentemente, os valores) do sistema de interesses dominante".

Neste nosso estudo parece-nos plausível afirmar que os participantes no mesmo têm a sua participação política enquadrada nos seguintes âmbitos:

- Caracterizada por atividades como inscrever-se, dedicar tempo e trabalho a um partido político, sendo membro activo do mesmo; participar num debate político; participar num comício; procurar convencer alguém a votar num

1. Alocução proferida pelo Bastonário da Ordem dos Enfermeiros na cerimónia de vinculação à profissão que decorreu a 4 de outubro de 2014 em Lisboa. 
certo candidato ou num determinado partido; expor-se a solicitações políticas; identificar-se politicamente; dedicar-se a uma campanha política; candidatar-se a um cargo eletivo e ocupar cargos públicos (Barbagli e Maccelli, 1985; Milbrath, 1965).

- Na classificação de Pizzorno (1966), estará ao nível do "profissionalismo político", caracterizado por uma ação inserida no sistema estatal e onde a solidariedade política prevalece.

- Nas dimensões propostas por Verba, Nie e Kim (1978) estará inserida na "atividade de campanha”.

- Na ótica de Teorell, Torcal \& Montero (2007) será uma “atividade partidária”, caracterizada por um canal de expressão representativo e onde o mecanismo de influência é a "voz" (enquanto atividade partidária, protesto e contacto).

- Perfil "conformista", na ótica do proposto por Kaase \& Marsh (1979), que se caracteriza pelo recurso às formas convencionais de participação.

Considerando a problemática da representação social da profissão que este fenómeno da participação política faz emergir, fez-se também uma opção de estudo que julgamos adequada, pelo interesse em conhecer a representação social da Enfermagem numa amostra bem delimitada e contextualizada, como são os enfermeiros candidatos nas eleições autárquicas. Foi uma opção que se revelou como natural, dado o carácter exploratório do presente trabalho.

Para essa análise, releva uma referência à Teoria das Representações Sociais elaborada por S. Moscovici em 1961, que no seu trabalho La Psychanalyse, Son Image et Son Public parte à procura da resposta a questões essenciais: Como constrói o homem a realidade? Quais os processos que tornam viável a comunicação e a organização dos comportamentos? Estas respostas implicam conceitos como o estereótipo, imagem, atitude, opinião, crenças, grupos de afiliação, entre outros.

Não obstante, Moscovici (1976) define representações sociais como:

um conjunto organizado de conceitos, proposições e explicações criadas na vida quotidiana no decurso da comunicação interindividual. São o equivalente na nossa sociedade, dos mitos e sistemas de crenças das sociedades tradicionais; podem ainda ser vistas como a versão contemporânea do "senso comum".

\section{Enquadramento Teórico}

A participação política dos enfermeiros pode ser analisada à luz das suas barreiras (Boswell, Cannon e Miller, 2005; Hanley, 1987; Chan e Cheng, 1999; Whitehead, 2003; Des Jardin, 2001) e dos seus facilitadores (Boswell, Cannon e Miller, 2005; Whitehead, 2003; Des Jardin, 2001), sendo possível operar interpretações integradas à luz do modelo conceptual da participação política dos enfermeiros (Hanley, 1987) ou do modelo de análise do grau de desenvolvimento da participação política dos 
enfermeiros (Cohen et al., 1996). Para qualquer uma das análises importa, porém, ter sempre presente o uso que os enfermeiros fazem dos canais de participação política (Chan e Cheng, 1999).

As barreiras à participação política dos enfermeiros compreendem diversos fatores, desde as elevadas cargas de trabalho até ao sentimento de impotência, passando por constrangimentos de tempo, discriminação com base no sexo e ausência de compreensão da complexidade do processo político (Boswell, Cannon e Miller, 2005). O dilema da autonomia dos enfermeiros na tomada de decisão nas instituições de saúde é alavancado pelo défice crescente destes profissionais, que contrasta com a sobredimensionada oferta de médicos e o aparecimento de novas profissões paramédicas. Torna-se lógico, assim, que a participação política dos enfermeiros se afigura crítica para atingir determinados objetivos pessoais e profissionais destes, ainda para mais num contexto onde uma profissão maioritariamente feminina funciona no seio de sociedades patriarcais (Hanley, 1987). Falk Rafael (1999; cit. por Whitehead, 2003) sustenta que os enfermeiros têm sido afastados por outros grupos profissionais do debate político sobre promoção da saúde por força da desvalorização que a conotação com um trabalho médico de menor relevância acarreta.

Adicionalmente, temos ainda a fragmentação do poder da profissão de enfermagem, que se constituiu, no estudo levado a cabo por Chan e Cheng (1999), como uma das principais barreiras à participação política dos enfermeiros. Durante a realização do seu estudo, os autores constataram a existência de 12.000 enfermeiros em Hong Kong e 20 grupos de enfermeiros cujos líderes apresentavam fraca coesão. De tal facto, resultava que nenhum dos líderes podia falar por todos os enfermeiros de Hong Kong a uma só voz. Também Des Jardin (2001) considera que a apatia política na Enfermagem pode ser atribuída a inúmeros fatores, incluindo a falta de conhecimento sobre o processo político e a elaboração de políticas públicas, sentimentos de incapacidade e a perceção de um conflito ético entre os valores profissionais e o envolvimento político.

O nível de preparação académica parece também funcionar como uma barreira relevante, facto que foi atestado no estudo levado a cabo por Hanley (1987) ao concluir que as enfermeiras pertencentes a organizações representativas da classe eram tão participativas quanto as professoras e engenheiras ao nível do votar, fazer campanha, ter atividade de base comunitária e protestar. Porém, este nível de participação só se verificava quando o grau académico era a licenciatura, constatando-se que níveis habilitacionais mais baixos estavam associados a uma menor participação política. Os preditores da participação e envolvimento político que mais se destacaram neste estudo foram o nível das habilitações (educação) e de vencimento.

Em termos de facilitadores da participação política dos enfermeiros Des Jardin (2001; cit. por Boswell, Cannon e Miller, 2005) estipula que os indivíduos envolvidos em atividades políticas identificam 3 pressupostos básicos que potenciam o seu envolvimento no processo político: experiência pessoal recente com um modelo político ativo; envolvimento com aspetos políticos quando ainda no contexto educativo; 
e oportunidades de emprego que proporcionem relações políticas. Catalano (2000, cit. por Boswell, Cannon e Miller, 2005) reforça esta perspetiva adicionando-lhe o interesse próprio enquanto facto necessário, na medida em que o mesmo modela o nível de alerta do indivíduo para os assuntos de carácter político. Des Jardin (2010; cit. por Boswell, Cannon e Miller, 2005) identificou diversos talentos ocultos possuídos pelos enfermeiros que catalisam o seu ativismo político. Por exemplo, os enfermeiros são excelentes negociadores, comunicadores, solucionadores de problemas e jogadores de equipa. Além disso, são frequentemente solicitados para gerir personalidades desafiantes, neutralizar circunstâncias potencialmente instáveis e gerir conflitos.

Todas estas habilidades ou talentos fazem dos enfermeiros agentes ideais para a arena política, na opinião do autor. Ele considera ainda que os enfermeiros possuem valores ligados ao cuidado individualizado de cada utente e à colaboração interprofissional, e que estes valores que fazem deles uma presença inultrapassável na formulação de políticas de saúde que sejam custo-efetivas. Além disso, na sua ótica, a enfermagem chegou a um patamar de prestígio onde a palavra "enfermeiro" é sinónimo de "defensor do utente", criando assim uma imagem de marca que é preciso defender. No entanto, considera também que o público não irá reconhecer os enfermeiros como seus defensores enquanto estes não começarem a desafiar o estado da arte em termos de saúde pública e determinantes sociais ao nível institucional, comunitário e nacional.

Whitehead (2003) defende, na linha do preconizado por Taylor (1995), Rush (1997), De Witt e Carnell (1999), Gebbie et al. (2000), Clifford (2000) e Cohen e Milone-Nuzzo (2001), que deve haver uma integração de conteúdos sobre o processo político nos currículos dos cursos de enfermagem, se se deseja que os enfermeiros sejam parte ativa na definição de políticas para os sistemas prestadores de cuidados de saúde. Na linha desta crítica, Conger e Johnson (2000; cit. por Whitehead, 2003) sustentam que a educação em enfermagem socializa os seus estudantes para um papel social e político letárgico. Para contrariar esta situação, preconizam que os currículos contenham objetivos de aprendizagem centrados nas forças políticas, fiscais e sociais que moldam os serviços de saúde, na mesma linha do defendido por Boswell, Cannon e Miller (2005) quando advogam a introdução do tema da participação política na educação pré e pós-graduada. Também Chan e Cheng (1999) sublinham que o processo político e a política em geral estão ausentes dos currículos dos cursos de enfermagem e que tal facto limita a capacitação dos enfermeiros para participarem neste âmbito.

De forma sistemática, Des Jardin (2001) propõe as seguintes alavancas facilitadoras da participação política dos enfermeiros:

- Educação e capacitação dos enfermeiros: as escolas de enfermagem precisam de incorporar assuntos relacionados com o processo político nos seus currículos, abordando o desenvolvimento de políticas mas também a forma de influenciar o processo político. 
- Organizações profissionais: as associações profissionais podem servir para apoiar os enfermeiros em termos de fornecimento de informação, apoio à elaboração de candidaturas políticas e apoio a iniciativas que visam o processo político e o desenvolvimento de políticas concretas.

- Educação do público: os enfermeiros estão em posição de educar o público sobre o seu papel no contexto político e sobre a importância da comunidade se envolver nas questões dos cuidados de saúde.

- Líderes transformacionais e estratégias de capacitação: os líderes da profissão precisam de deter competências apuradas em tomada de decisão ética de forma a poderem comunicar perspetivas futuras em que tem de se assumir riscos ao mesmo tempo que se abraça a mudança e se capacita os outros.

Relevantes quer para as barreiras quer para os facilitadores da participação política dos enfermeiros são os canais dessa mesma participação. Nesse âmbito, Chan e Cheng (1999) identificaram os seguintes canais:

1. Envolver-se em atividades eleitorais, tais como votar, contribuir para uma campanha, trabalhar para um candidato ou qualquer atividade que procure influenciar o resultado do processo eleitoral;

2. Organizar grupos formais como partidos políticos ou grupos informais como grupos de interesses comuns com o intuito de influenciar a política governamental;

3. Fazer lobbying junto do governo ou de altos funcionários com o intuito de alcançar objetivos individuais ou do grupo;

4. Utilizar os meios de comunicação social para influenciar o processo de decisão político;

5. Fazer petições;

6. Usar comportamento destrutivo ou violento.

No estudo que levaram a cabo acerca da participação política dos enfermeiros os autores concluíram que a maior parte dos enfermeiros desconhecia quais os canais adequados para a sua participação política e que consideravam não ter o tempo, energia e recursos para serem politicamente ativos, além de não se reconhecerem como tendo o poder necessário para influenciar políticas. Também Des Jardin (2001) se debruça sobre a questão dos canais de participação ao estabelecer a destrinça entre a abordagem tradicional e não tradicional à política. Diz o autor que a abordagem tradicional à política é reativa e que, tipicamente, as pessoas consideram que a ação política é composta por lobbying, envio de missivas, votação e outros meios convencionais para influenciar os políticos e as iniciativas de políticas públicas. A abordagem não tradicional, em contraponto e no que concerne à participação dos enfermeiros, será proativa, sendo que um dos seus componentes é a educação do público em matérias como os cuidados de saúde preventivos, as dotações de pessoal 
nos hospitais, o sistema de financiamento do sistema de saúde e a estrutura política do sistema de cuidados de saúde.

De forma a sistematizar o já referido, recorremos ao modelo conceptual da participação política dos enfermeiros, proposto por Hanley (1987) e constante da figura 1. Recorremos a este modelo na medida em que o mesmo é sensível ao facto da maior parte dos elementos da profissão serem mulheres, com tudo o que isso acarreta em termos de representações e posições sociais (Hanley, 1987). Ou seja, a autora procede a uma comparação da participação política das enfermeiras com a das professoras e das engenheiras, procurando diferenças entre os 3 grupos sem descurar as condicionantes sociais inerentes ao facto de serem mulheres, o que poderia enviesar os seus achados. Considerando que a profissão de enfermagem em Portugal é caracterizada por ter $82 \%$ dos seus inscritos ${ }^{[2]}$ como sendo do sexo feminino, o modelo proposto por Hanley (1987) afigura-se-nos como um contributo válido para o estudo da participação política dos enfermeiros em Portugal.

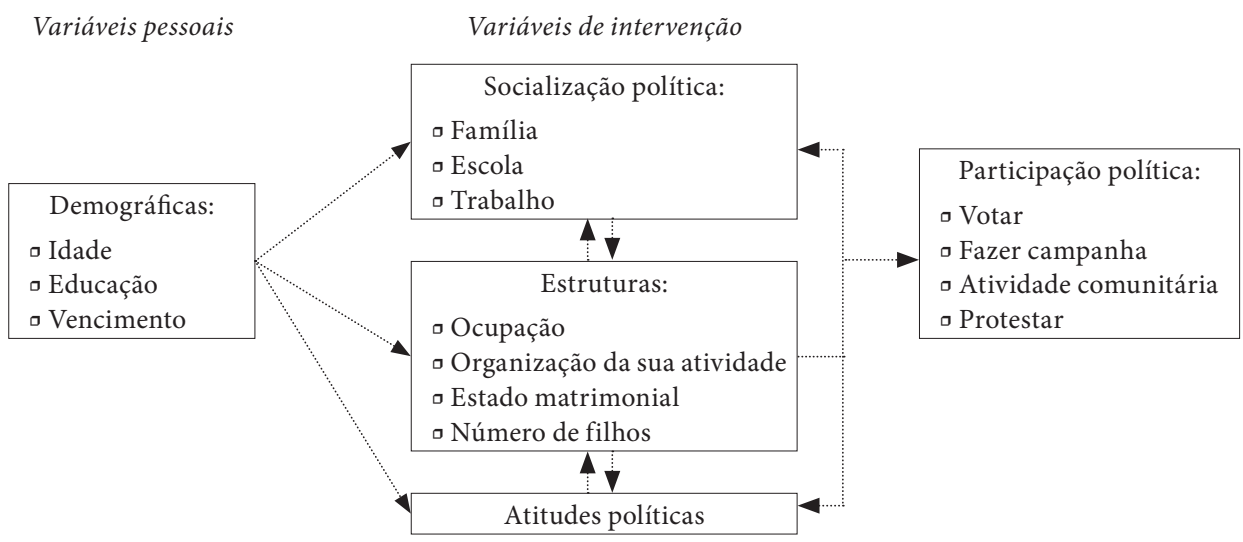

Figura 1. Modelo conceptual da participação política dos enfermeiros Fonte: Adaptado de Hanley (1987).

Por seu lado, Cohen (1996) propõe um modelo de análise do grau de desenvolvimento da participação política dos enfermeiros (tabela 1) ao qual recorremos para interpretar os resultados obtidos com o nosso estudo.

Escolhemos este modelo para interpretação dos resultados porque consideramos crítico, para início do estudo do estado da arte neste âmbito, uma caracterização do grau de desenvolvimento da participação política dos enfermeiros. Esta análise

2. Disponível em: <http://www.ordemenfermeiros.pt/membros/PublishingImages/2017_DadosEstatisticos_ Nacional.pdf $>$ (consultado a 26/2/2018). 
do grau de desenvolvimento revela-se pertinente não só no contexto internacional, como nos demonstra o próprio autor mas também o Conselho Internacional de Enfermagem ${ }^{[3]}$, mas especialmente no contexto nacional, face à inexistência de artigos (na procura por nós levada a cabo) que façam prova dessa evidência em Portugal. Não obstante essa participação ser repetidamente referida como necessária e imperativa tanto pelo regulador profissional (Ordem dos Enfermeiros, 2010; 2013 ${ }^{[4]}$ ) como por diversos líderes da profissão ${ }^{[5]}$.

Tabela 1. Modelo de análise do grau de desenvolvimento da participação política dos enfermeiros

\begin{tabular}{|c|c|c|c|c|}
\hline & $\begin{array}{l}\text { Fase } 1 \\
\text { (entrar) }\end{array}$ & $\begin{array}{c}\text { Fase } 2 \\
\text { (interesse próprio) }\end{array}$ & $\begin{array}{c}\text { Fase } 3 \\
\text { (sofisticação } \\
\text { política) }\end{array}$ & $\begin{array}{c}\text { Fase } 4 \\
\text { (liderar o caminho) }\end{array}$ \\
\hline $\begin{array}{l}\text { Natureza } \\
\text { da Ação }\end{array}$ & $\begin{array}{l}\text { Reativa, com enfo- } \\
\text { que nos assuntos da } \\
\text { enfermagem }\end{array}$ & $\begin{array}{l}\text { Reativa a assuntos } \\
\text { da enfermagem mas } \\
\text { a abranger assuntos } \\
\text { mais amplos }\end{array}$ & $\begin{array}{l}\text { Proativa em assun- } \\
\text { tos de enfermagem } \\
\text { e mais outros mais } \\
\text { amplos }\end{array}$ & $\begin{array}{l}\text { Proativa na lide- } \\
\text { rança e na definição } \\
\text { da agenda para um } \\
\text { grupo amplo de } \\
\text { políticas sociais e de } \\
\text { saúde }\end{array}$ \\
\hline Linguagem & $\begin{array}{l}\text { A aprender a lingua- } \\
\text { gem política }\end{array}$ & $\begin{array}{l}\text { A usar linguagem } \\
\text { específica da enfer- } \\
\text { magem }\end{array}$ & $\begin{array}{l}\text { Uso de vocábulos } \\
\text { e retórica típica de } \\
\text { políticas de saúde }\end{array}$ & $\begin{array}{l}\text { Introdução de ter- } \\
\text { mos que conseguem } \\
\text { reorganizar o debate }\end{array}$ \\
\hline $\begin{array}{l}\text { Construção } \\
\text { de associa- } \\
\text { ções }\end{array}$ & $\begin{array}{l}\text { Consciência política; } \\
\text { participação ocasio- } \\
\text { nal em associações }\end{array}$ & $\begin{array}{l}\text { Associações forma- } \\
\text { das entre organiza- } \\
\text { ções de enfermeiros }\end{array}$ & $\begin{array}{l}\text { Associações entre } \\
\text { grupos de enfermei- } \\
\text { ros; participação } \\
\text { cativa e significativa } \\
\text { em grupos de saúde } \\
\text { mais amplos }\end{array}$ & $\begin{array}{l}\text { Dão início a associa- } \\
\text { ções que extravasam } \\
\text { a enfermagem e se } \\
\text { ocupam de assuntos } \\
\text { mais amplos das } \\
\text { políticas de saúde }\end{array}$ \\
\hline $\begin{array}{l}\text { Enfermei- } \\
\text { ros como } \\
\text { definidores } \\
\text { de políticas }\end{array}$ & $\begin{array}{l}\text { Casos isolados de } \\
\text { enfermeiros a serem } \\
\text { nomeados para posi- } \\
\text { ções políticas, prin- } \\
\text { cipalmente fruto de } \\
\text { realizações pessoais }\end{array}$ & $\begin{array}{l}\text { As associações } \\
\text { profissionais conse- } \\
\text { guem colocar enfer- } \\
\text { meiros em posições } \\
\text { relacionadas com a } \\
\text { enfermagem }\end{array}$ & $\begin{array}{l}\text { As associações de } \\
\text { enfermeiros conse- } \\
\text { guem colocar enfer- } \\
\text { meiros em posições } \\
\text { relacionadas com a } \\
\text { política de saúde }\end{array}$ & $\begin{array}{l}\text { Muitos enfermeiros } \\
\text { conseguem ocupar } \\
\text { cargos políticos e } \\
\text { de direção por força } \\
\text { do valor e conheci- } \\
\text { mento reconhecidos } \\
\text { à profissão }\end{array}$ \\
\hline
\end{tabular}

Fonte: Adaptado de Cohen (1996).

3. Disponível em: <http://www.jornalenfermeiro.pt/entrevistas/item/1651-icn-quer-ter-voz-ativa-na-definicao-de-politicas-para-a-saude.html> (consultado a 27/2/2108).

4. Disponível em: <http://www.ordemenfermeiros.pt/comunicacao/Paginas/ParticipacaoenfermeirosdefinicaopoliticassaudedominadebateMinisterio_entidades_deputados_areaSaude.aspx $>$ (consultado a 27/2/2018).

5. Disponível em: <http://www.jornalenfermeiro.pt/entrevistas/item/1568-speo-quer-mais-enfermeiros-na-definicao-de-politicas-de-saude.html> (consultado a 27/2/2018). 
Consideramos, alicerçados no já por nós argumentado, que a análise da participação política dos enfermeiros implica uma incursão pela representação social que estes têm da sua profissão, na medida em que esta é influenciada pela perceção que a própria sociedade tem dela. Consideramos haver uma retroalimentação de representações, para as quais os processos de socialização profissional e as próprias características sociológicas da profissão contribuem, acabando por influenciar os termos e a medida da participação política dos seus elementos. É neste âmbito que recorremos à teoria do núcleo central elaborada por Abric $(1975,1984)$.

Esta teoria considera que a representação social tem uma estrutura interna organizada à volta de um "núcleo central". Este núcleo é o elemento ou conjunto de elementos que dá à representação a sua coerência e significado global. O "núcleo central” é, também, o organizador e estabilizador da representação. A ausência ou transformação dos seus elementos provoca uma desorganização do significado da representação.

Os outros elementos da representação, chamados "periféricos", organizam-se à volta do núcleo central. Constituem a parte mais acessível, e quantitativamente maior da representação, e o essencial do seu conteúdo, compreendendo o "sistema periférico" as informações retidas, selecionadas e interpretadas, os julgamentos formulados a propósito do objeto e do seu envolvente, os estereótipos e as crenças.

O "sistema periférico" constitui o complemento indispensável ao "sistema central", do qual depende. Enquanto o sistema central é essencialmente normativo, o sistema periférico é essencialmente "funcional", ou seja, graças a ele a representação pode ancorar-se na realidade do momento presente.

O núcleo central (ou núcleo estruturante) é caracterizado por uma "função geradora" e uma "função organizativa". Possui ainda uma propriedade essencial que é a estabilidade.

\section{Questões de Investigação/Hipóteses}

A questão de partida para o presente estudo foi: como é que a identidade profissional dos enfermeiros molda a sua participação política ao nível autárquico?

Esta questão surgiu na senda das considerações conceptuais acima dispostas no que concerne à participação política dos enfermeiros, que não raras vezes nos remetem para uma articulação entre o grau de participação dos enfermeiros e as características inerentes à sua profissão.

A razão pela qual se optou pelas eleições autárquicas e não outras está relacionado com o facto de serem aquelas que envolvem o maior número de candidatos, aumentando assim não só a probabilidade de encontrar candidatos que fossem enfermeiros mas também a oportunidade de recolher dados nesse momento eleitoral preciso. 


\subsection{Metodologia}

Para a definição da metodologia de investigação recorreu-se aos contributos de Quivy e Campenhoudt (2005), Albarello et al. (2005), Ribeiro (2010), Bardin (2006), Fortin (2003), Abric (1975, 1984) e Vergés (1992).

Considerando a natureza da problemática em apreço e a inexistência de um estudo semelhante em Portugal, que influenciou o carácter exploratório do presente, optou-se por fazer uma leitura do enquadramento teórico relativo à participação política dos enfermeiros e temas conexos de forma a ajudar a delimitar o objeto de análise e a construção do instrumento de análise das respostas obtidas com recurso a um questionário semiestruturado.

O procedimento utilizado consistiu no envio de um questionário recorrendo ao Googledocs. Para identificar os destinatários do questionário enviou-se uma mensagem de correio eletrónico massivo para contactos identificados como sendo enfermeiros e candidatos a órgãos autárquicos, solicitando a identificação de outros enfermeiros que se enquadrassem no perfil pretendido. Recorreu-se também às respetivas páginas no Facebook. Realizaram-se 3 envios espaçados por uma semana entre cada um, de forma a acomodar novos contatos que entretanto se foram recolhendo durante a aplicação do questionário.

Apurados 80 enfermeiros que correspondiam ao perfil pretendido, candidatos a órgãos autárquicos, foi enviado o questionário para cada um deles. Foi, assim, obtida uma amostra de conveniência constituída por 30 enfermeiros que responderam ao questionário. Considerando que existem 305 municípios e 3091 freguesias, com listas com centenas de candidatos envolvidos, é de se considerar que o universo de enfermeiros envolvidos em eleições autárquicas seja bem maior que os 80 apurados desta forma.

Como técnica de análise dos dados utilizou-se a análise de conteúdo (Bardin, 2006) para os dados referentes às mais-valias que cada respondente considerava trazer para a candidatura onde estava integrado. Para a parte da representação social da enfermagem recorreu-se a uma análise lexicográfica através do programa informático desenvolvido por Vergés (1992), tendo como referência a teoria do núcleo central de Abric $(1975,1984)$. Procedeu-se à estatística descritiva dos restantes dados.

Após a recolha dos dados procedeu-se: à análise estatística dos dados; à análise de conteúdo das respostas obtidas às perguntas sobre as mais-valias para a candidatura que integravam; e à análise lexicográfica das respostas à questão de evocação sobre Enfermagem, visando encontrar o núcleo central e periférico da representação social da Enfermagem.

\section{Resultados}

\subsection{O enfermeiro candidato}

O enfermeiro-tipo candidato tem uma idade média de 41 anos, é masculino, enfermeiro há 17 anos, de cuidados gerais, está na prestação de cuidados num hospital e candidata-se pelo Partido Socialista (PS). 
Em termos de idade o valor mínimo obtido é de 24 anos e o máximo de 57 . Os respondentes são maioritariamente masculinos $(n=20 ; 66 \%)$ e em termos de título profissional 50\% detêm o título de enfermeiro especialista, sendo a mais representativa a especialidade em Enfermagem de Reabilitação (13\%).

Em termos de entidade empregadora a distribuição é a seguinte: hospital/centro hospitalar 60\%, ACES 7\%, ARS 10\%, sector privado e social 13\% e instituição de ensino superior $10 \%$.

Em termos de função na entidade empregadora 20 (67\%) encontram-se na prestação de cuidados, 7 (23\%) têm funções de gestão/direção e 3 (10\%) de docência.

Em termos de anos de exercício profissional a média obtida é de 17 anos, com um valor máximo de 36 anos e um mínimo de 2.

Em termos de partido/movimento/coligação pelo qual se candidatam a distribuição é ampla. Nominalmente e percentualmente os resultados são: Coligação Democrática Unitária (CDU) 3 (10\%); PS 9 (30\%); Bloco de Esquerda (BE) 1 (3\%); Partido Popular (CDS-PP) 4 (14\%); Independente 4 (14\%); Partido Social Democrata (PSD) 7 (23\%); Partido da Terra (MPT) 1 (3\%); PSD/CDS-PP 1 (3\%).

\subsection{A enfermagem na candidatura}

Em termos de órgãos autárquicos 10 (33\%) candidatam-se à Câmara Municipal, 7 (23\%) à Assembleia Municipal e 13 (44\%) à Assembleia de Freguesia. Dos candidatos à Câmara Municipal 3 identificam-se como candidatos a presidente da mesma, sendo dois suportados por uma candidatura do CDS-PP e um pelo BE.

Só o PS apresenta candidatos às 3 estruturas autárquicas.

$77 \%$ dos inquiridos afirmam estar identificados como enfermeiros nos materiais propagandísticos das candidaturas.

Em termos de cargos no movimento/partido 57\% dos inquiridos são filiados em partidos/movimentos de cidadãos, sendo que destes, $37 \%$ são membros dos órgãos concelhios e $20 \%$ são apenas militantes.

No total dos inquiridos, $63 \%(n=19)$ nunca se haviam candidatado em eleições autárquicas, sendo que dos candidatos pelo PS 67\% encontram-se nesta situação. No caso da CDU e MPT este valor é de $100 \%$, 75\% para o CDS-PP e $71 \%$ para o PSD. Quanto aos independentes 75\% já se haviam candidatado em eleições anteriores, sendo que para o BE e para a coligação PSD/CDS-PP este valor é de $100 \%$.

Para $60 \%$ dos inquiridos o facto de ser enfermeiro teve algum peso na decisão que tomou para se candidatar.

$90 \%$ dos programas $(\mathrm{n}=27)$ apresentam medidas concretas na área da saúde.

$70 \%(\mathrm{n}=21)$ dos inquiridos assume ter uma influência superior ao grau 5 (numa escala de 0 a 10) nas propostas programáticas na área da saúde, sendo que $27 \%$ (8) indica um grau de influência igual a 7.

Os graus médios de influência por partido/movimento são: CDU 7.6; PS 7.4; BE 10 ( $\mathrm{n}=1)$; CDS-PP 7.25; independentes 6; PSD 4.6; MPT 9 ( $\mathrm{n}=1)$; PSD/CDS-PP 4 (n=1). Os que apresentam maior amplitude interna são os independentes (oscilam entre o 
grau 1 e 10) seguidos pelo PSD (oscila entre o grau 1 e 9). A menor variação é verificada na CDU (1 ponto de variação entre valor máximo e mínimo) e no CDS-PP (também 1 ponto de variação). Para a análise da amplitude interna não se consideraram aqueles que apresentaram $n=1$.

Em termos de grau de influência no programa, por cargo autárquico, os resultados apresentam os seguintes valores médios: Assembleia Municipal 5.4; Câmara Municipal 8.4; Assembleia de Freguesia 5.8, donde se conclui que são aqueles que se candidatam a cargos no executivo camarário que apresentam o maior grau de influência (auto percecionada) nas propostas da área da saúde.

Quando inquiridos sobre as mais-valias que consideram trazer para as respetivas listas de candidatura, os respondentes referem 33 mais-valias, sendo que dessas, apenas 29 se consideraram elegíveis para unidades de registo (Bardin, 2006).

Daí emergiram 3 categorias e 8 subcategorias, como se pode constatar no gráfico 1 que demonstra a frequência verificada ao nível de cada uma.

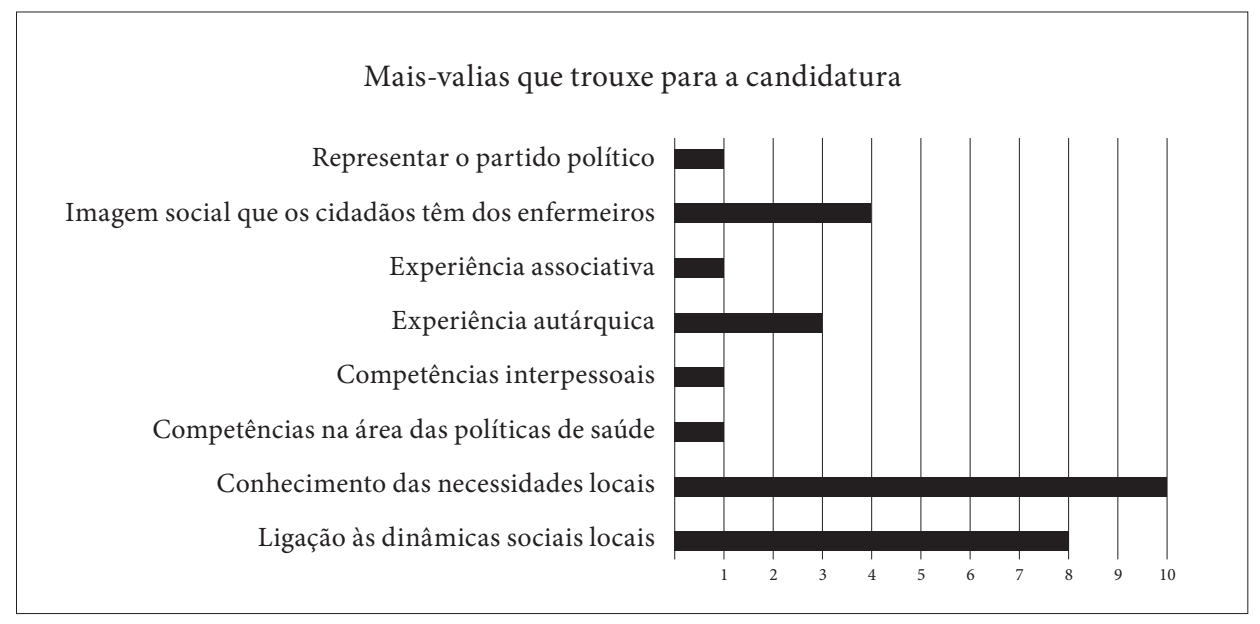

Gráfico 1: Mais-valias que trouxe para a candidatura

\subsection{Representação social da enfermagem}

As respostas recolhidas da questão de evocação foram submetidas a uma análise lexicográfica através do programa informático desenvolvido por P. Vergés (1992). A análise classifica os termos evocados de acordo com a frequência (número de vezes em que surge no grupo) e a ordem média de evocação (rapidez de aparecimento). Como se verifica na leitura da tabela 2, foi possível determinar, simultaneamente, o sistema central e periférico da representação social da Enfermagem do grupo em causa.

Foram evocados 137 termos diferentes num total de 201 palavras. 
Tabela 2. Núcleo Central e S. Periférico: termos evocados, segundo as frequências e ordem média de evocação

\begin{tabular}{|c|c|c|c|c|c|c|}
\hline \multirow{5}{*}{$\mathrm{F}>5$} & \multirow[t]{2}{*}{++} & \multicolumn{2}{|l|}{$<4.39$} & \multicolumn{2}{|r|}{$>4.39$} & \multirow{3}{*}{$\begin{array}{c}+- \\
\text { Média } \\
6.00\end{array}$} \\
\hline & & & Média & & & \\
\hline & 5 & Ajuda & 2.80 & 6 & Tratar & \\
\hline & 15 & Cuidar & 1.80 & & & \\
\hline & 8 & Saúde & 3.12 & & & \\
\hline \multirow{11}{*}{$\mathrm{F}<5$} & 2 & Capacidade & 1.50 & 2 & Ética & 8.50 \\
\hline & 2 & Desemprego & 2.50 & 2 & Família & 5.50 \\
\hline & 2 & Dever & 1.50 & 3 & Gestão & 6.30 \\
\hline & 4 & Humanismo & 2.25 & 2 & Profissão & 6.00 \\
\hline & 2 & Prevenção & 2.00 & 2 & Promover & 5.50 \\
\hline & 2 & Proximidade & 1.00 & 3 & Reabilitar & 4.60 \\
\hline & & & & 4 & Responsabilidade & 6.50 \\
\hline & & & & 2 & Saber-estar & 3.00 \\
\hline & & & & 2 & Saber-fazer & 5.00 \\
\hline & & & & 2 & Saber-ser & 3.00 \\
\hline & -+ & & & & & -- \\
\hline
\end{tabular}

Nota: ++ Núcleo da representação; +- Nível que envolve o núcleo; -+ Nível de menor centralidade; -- Nível mais periférico.

A média da ordem de evocação foi de 4,39 para os sujeitos dividindo o eixo vertical as evocações acima e abaixo desse valor de rapidez da ocorrência no grupo.

A média da ordem de evocação (possível entre 1 e 8) indica a maior ou menor importância dos termos para os sujeitos que os produziram. A análise das frequências dos termos evocados põe em evidência uma hierarquização com base no número de vezes que é evocado cada um deles.

Podemos falar de duas dimensões no conjunto de resultados apresentados. Uma dimensão coletiva, dada pelo número de vezes que uma palavra é enunciada no total de palavras (frequência), e outra mais individual (ordem de evocação), em que a média obtida se refere à distribuição estatística hierarquicamente estabelecida pelo sujeito para cada termo. É na combinação destas duas dimensões que resulta a objetivação da representação da Enfermagem e paralelamente a estrutura interna.

Ao classificarmos os termos segundo o cruzamento dos eixos que representam as frequências e a ordem de evocação obtemos os quadrantes, que representam o sistema central e periférico.

Em cima e à esquerda os termos verdadeiramente salientes e significativos para toda a população, em baixo e à direita as palavras menos frequentes e citadas em último lugar. No primeiro está o núcleo central da representação e no segundo os elementos periféricos. Os outros dois quadrantes dão-nos informação contraditória em relação aos critérios que os dois eixos exprimem (frequência e ordem de evocação), sendo interpretados (Vergès, 1994) como traduzindo uma ambiguidade e que correspondem a uma zona de desequilíbrio e origem de futuras mudanças da representação. 
O núcleo central da amostra aqui analisada inclui os termos "ajuda”, "cuidar" e "saúde". No nível periférico, verifica-se uma maior diversidade de termos evocados pelo grupo. Assim, podemos considerar que os termos “ajuda", "cuidar" e "saúde” determinam a forma como este grupo encara a Enfermagem. Tratando-se de conceitos menos operacionais e descritivos, dada a variedade possível de significados individualmente considerados, permitem o consenso e a estabilidade da representação da Enfermagem. Como seria de esperar, os termos mais descritivos e precisos, como desemprego ou proximidade estão na estrutura da representação que corresponde ao interface com o quotidiano e à situação mais imediata da Enfermagem, surgindo termos contraditórios em relação à profissão.

\section{Conclusão}

As principais limitações metodológicas prenderam-se com o facto de não se dispor de estudos prévios similares que permitissem um ajustamento das várias opções que foram sendo tomadas ao longo da distribuição e análise dos dados.

Somos levados a considerar, partindo dos resultados do presente estudo, que o enfermeiro-tipo candidato a eleições autárquicas apresenta as seguintes características:

- Do ponto de vista socioprofissional é enfermeiro de cuidados gerais, masculino e está na prestação direta de cuidados, trabalhando há cerca de 2 décadas e oriundo do contexto hospitalar. Identifica-se como enfermeiro para efeitos de eleição política e tem atividade partidária. O facto da maioria dos enfermeiros respondentes a este estudo ser masculino, traz a necessidade de analisar em maior profundidade as questões do género e da participação política dos enfermeiros, como suscitado por Hanley (1987).

- No respeitante à sua visão da profissão revê-se numa profissão e sentir profissional alicerçados na ajuda e no cuidar do próximo, sendo que o facto de ser enfermeiro contribui para as suas opções políticas e influencia a sua atividade partidária. Parece-nos que o constructo social que é feito da profissão pelos próprios enfermeiros é incorporado na sua participação política e nas opções programáticas que defendem.

- Relativamente à sua visão da política autárquica no âmbito da saúde, identifica a proximidade às populações como um aspeto central e escolhe o cidadão como foco da sua preocupação, o que está alinhado com a sua visão da profissão.

Recorrendo ao modelo de análise do grau de desenvolvimento da participação política dos enfermeiros, desenvolvido por Cohen (1996), os resultados obtidos apontam-nos para a inclusão da nossa amostra nos seguintes graus de participação:

- Natureza da Ação - fase 4

- Linguagem - fase 2 
- Construção de associações - não aplicável

- Enfermeiros como definidores de políticas - fase 1

Considera-se que o número de enfermeiros apurados como candidatos autárquicos, 80 , constitui um valor expressivo do envolvimento destes profissionais na vida política. Cremos que serão mais, mas que por limitações de tempo para a realização do estudo não foi possível identificar e contactar, pelo que se considera interessante continuar a realizar este tipo de análise, entrando em linha de conta inclusive com os resultados dos mandatos autárquicos daqueles que participaram neste primeiro estudo. Procurar-se-á desta forma avaliar de que forma consubstanciaram aquilo que consideravam ser as suas prioridades políticas na área da saúde e de que forma o exercício de um mandato político opera mudanças nas perceções sobre o seu conteúdo e desígnio, assim como a influência que a profissão exerce neste.

Quanto à representação social da enfermagem, e em particular a teoria do núcleo central, a que corresponde a sua componente mais estável e duradoura, resistente à mudança, consideramos pertinente aprofundar caminhos de investigação no sentido de determinar, por um lado, a influência do núcleo periférico nas opções políticas dos enfermeiros bem como a sua mutabilidade e os fatores que concorrem para a mesma, e por outro, a extensão na qual o núcleo central condiciona e determina a forma como os enfermeiros incorporam o seu ser profissional na sua ação política. Além disso, afigura-se-nos igualmente relevante alargar esta abordagem a outras profissões, no sentido de avaliar se a própria questão do núcleo central se pode revelar como aspeto preditivo da predisposição dos políticos para determinados problemas e formas de agir em função do seu enquadramento profissional.

Propõe-se que em trabalhos futuros se aprofundem as seguintes questões no desenho dos estudos:

- Os 3 pressupostos básicos que Des Jardin (2001; cit. por Boswell, Cannon e Miller, 2005) considera ser potenciador do envolvimento das pessoas no processo político: experiência pessoal recente com um modelo político ativo; envolvimento com aspetos políticos quando ainda no contexto educativo; e oportunidades de emprego que proporcionem relações políticas;

- A carga formativa na formação pré e pós-graduada, relacionada com políticas públicas, que os respondentes tiveram;

- Avaliar de que forma cada respondente utiliza os canais da participação política como identificados por Chan e Cheng (1999);

O presente estudo, por força das limitações relacionadas com a necessidade de se garantir alguma adesão dos respondentes, num contexto onde os pedidos de participação por via das redes sociais eram feitos a pessoas com as quais nunca se contactara, não se debruçou sobre estas questões em profundidade. Todavia, enquanto estudo exploratório, permite lançar algumas pistas para questões pertinentes a desenvolver em futuros estudos neste âmbito, e contribui com alguma evidência para 
as diferentes teorias que emolduram a análise da participação política de determinados grupos profissionais, nomeadamente os enfermeiros.

Data de receção: 25/10/2017

Data de aprovação: 06/02/2019

\section{Referências}

Abric, J. (1994). Pratiques Sociales et Représentations. Paris: Presses Universitaires de France. Albarello, L., et al. (2005). Práticas e métodos de investigação em ciências sociais. Lisboa: Gradiva.

Barbagli, M. \& Maccelli, A. (1985). La partecipazione Politica a Bologna. Bologna: Il Mulino. Bardin, L. (2006). Análise de conteúdo. Lisboa: Edições setenta.

Borba, J. (2012). Participação política: uma revisão dos modelos de classificação. Sociedade e Estado, 27 (2), 263-288.

Boswell, C., Cannon, S. \& Miller, J. (2005). Nurses' political involvement: responsibility versus privilege. Journal of professional nursing, 21 (1), 5-8.

Carnegie, E. \& Kiger, A. (2009). Being and doing politics: an outdated model or $21^{\text {st }}$ century reality. Journal of Advanced Nursing 65 (9), 1976-1984.

Chan, S. \& Cheng, B. (1999). Political participation in Hong Kong: a study. Journal of Nursing Management, 7, 167-175.

Cohen, S. et al. (1996). Stages of nursing's political development: where we've been and where we ought to go, Nurs Outlook, 44, 259-266.

Des Jardin, K. (2001). Political involvement in nursing - education and empowerment. AORN Journal, 74 (4), 467-475.

Hanley, B. (1987). Political participation: how do nurses compare with other professional women. Nursing Economics 5 (4), 179-185.

Fortin, M. (2003). O processo de investigação - da conceção à realização. Loures: Lusociência.

Fyffe, T. (2009). Nursing shaping and influencing health and social care policy. Journal of Nursing Management, 17, 698-706.

Gesse, T. (1991). Political participation behaviors of nurse-midwives. Journal of Nurse-Midwifery, 36, 184-191.

PayScale. (01.05.2015). College Salary Report in 2014. Disponível em <http://www.payscale. com/college-salary-report-2014> [consultado a 01/05/2015].

Ordem do Enfermeiros. (2017). Dados Estatísticos de Membros Activos em Território Nacional. Disponível em <http://www.ordemenfermeiros.pt/membros/PublishingImages/2017_DadosEstatisticos_Nacional.pdf> [consultado a 26/2/2018]. 
Jornal do Enfermeiro. (2017). ICN quer ter voz ativa na definição de políticas para a saúde. Disponível em <http://www.jornalenfermeiro.pt/entrevistas/item/1651-icn-quer-ter-voz-ativa-na-definicao-de-politicas-para-a-saude.html> [consultado a 27/02/2018].

Jornal do Enfermeiro. (2017). SPEO quer mais enfermeiros na definição de políticas de saúde. Disponível em <http://www.jornalenfermeiro.pt/entrevistas/item/1568-speo-quer-mais-enfermeiros-na-definicao-de-politicas-de-saude.html> [consultado a 27/02/2018].

Moliner, P. (1994), Le modèle bi-dimensionnel des représentations sociales, European Journal of Social Psychology, 27: 687-702.

Moscovici, S. (1989). Des représentations collectives aux représentations sociales: pour une histoire. In D. Jodelet (Ed.), Représentations sociales: un domaine en expansion (pp. 62-85). Paris: Puf.

Ordem dos Enfermeiros (2010). Revista da Ordem dos Enfermeiros, 33, 4-14.

Pasquino, G. (2005). Curso de Ciência Política. Cascais: Principia.

Quivy, R. \& Campenhoudt, L. (2005), Manual de Investigação em Ciências Sociais. Lisboa: Gradiva.

Ribeiro, J. (2012). Metodologias de Investigação em Psicologia e Saúde. Porto: Legis Editora.

Whitehead, D. (2003). The health-promoting nurse as a health policy career expert and entrepreneur, Nurse education today, 23, 585-592.

Wilson, D. (2002). Testing a theory of political development by comparing the political action of nurses and nonnurses, Nurs Outlook, 50, 30-34. 


\section{Sobre os autores}

BRUNO DE NORONHA GOMES é Enfermeiro Especialista em Reabilitação, a exercer como enfermeiro coordenador no Estabelecimento Prisional de Sintra. Mestre em Políticas de Desenvolvimento de Recursos Humanos e doutorando em Administração em Saúde no ISCSP-ULisboa.

JORGE ADELINo CUNHA Ribeiro PIRES é Enfermeiro Especialista em Saúde Mental e Psiquiatria, Oficial Enfermeiro na Direção de Saúde Militar (EMGFA). Mestre em Comportamento Organizacional, autor e coautor de diversos livros (Atlas da Psicologia, Prometeu Liberto: Itinerários de Droga em Medicina Comportamental, Alcoolismo e Toxicodependências: Manual Técnico 2, Em torno da Psicologia: Homenagem a Jorge Correia Jesuíno). Presidente da Associação Portuguesa de Enfermagem Militar.

\section{About the authors}

BRUNO DE NORONHA GOMES is a Nurse Specialist in Rehabilitation, currently working as a coordinator nurse at Sintra Prison. He holds a master's degree in Human Resources Development Policies and is a PhD student in Health Administration at ISCSP-ULisboa.

JORGE ADELINo CUnHA RIBEIRo PIRES is a Nurse Specialist in Mental Health and Psychiatry, Nurse Officer in the Military Health Department (EMGFA), holds a master's degree in Organizational Behavior, author and co-author of several books (Atlas da Psicologia, Prometeu Liberto: Itinerários de Droga em Medicina Comportamental, Alcoolismo e Toxicodependências: Manual Técnico 2, Em torno da Psicologia: Homenagem a Jorge Correia Jesuíno). President of the Portuguese Association of Military Nursing. 